\title{
Is Our Food Safe from Pesticides?'
}

\author{
Frederick M. Fishel ${ }^{2}$
}

\section{Producing the Nation's Food Supply}

The American public relies on $2 \%$ of its citizens to produce its food supply. Growers of the food supply have adopted the use of integrated pest management (IPM) because it is no longer possible to rely solely on chemical pesticides to prevent unacceptable crop losses. According to the U.S. Environmental Protection Agency (EPA), IPM is the coordinated use of pest and environmental information and available pest control methods to prevent unacceptable levels of damage by the most economical means with the least possible hazard to people, property, and the environment. Scientific IPM strategies give the grower economic incentives for sustaining long-term crop protection with minimal disruption to the environment. The agricultural community typically will use pesticides sparingly as part of the IPM strategy whenever proven alternatives are not available for pest control.

In the late 1970s, there was minimal organized pest scouting on vegetable acreage in Florida. Chemical pesticides were used heavily to combat Florida pests. These practices were not sustainable economically or environmentally because of the potential for widespread resistance and crop failures. Growers can no longer rely on broad-spectrum pesticides and have to incorporate several alternative practices for pest management. They have adopted multitactic, ecologically based IPM by selecting the best available technologies for reducing pest risk in their farming systems while maintaining economic viability. In Florida, tomato and pepper producers continue to be among the greatest IPM success stories. An estimated $75 \%$ of the tomato acreage is scouted twice weekly and sprayed only as necessary (Figure 1).

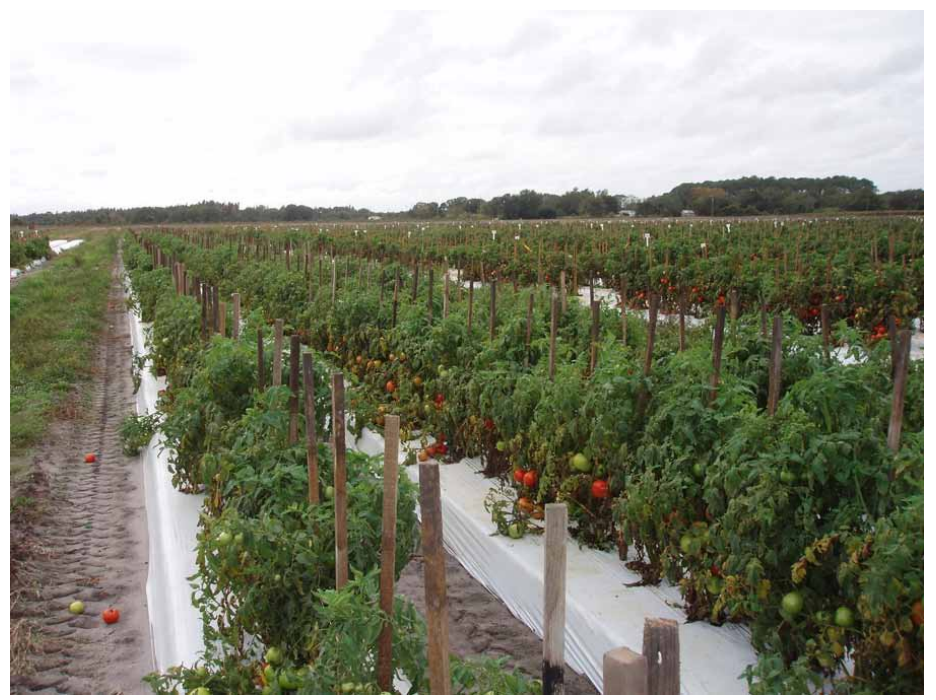

Figure 1. An estimated $75 \%$ of Florida's tomato acreage is scouted twice weekly and sprayed only as necessary. Credits: UF/IFAS Pesticide Information Office

Control of key Florida crop pests often incorporates applications of reduced-risk pesticides into the management plan. The EPA deems a pesticide a reduced-risk pesticide if it accomplishes at least one of the following: it presents a reduced risk to human health, nontarget organisms, water, and environmental resources, or it broadens the adoption of IPM strategies. In tomato production, for example, the number of insecticide applications has been reduced by

1. This document is PI230, one of a series of the Agronomy Department, Florida Cooperative Extension Service, Institute of Food and Agricultural Sciences, University of Florida. Original publication date June 2010. Revised March 2013. Visit the EDIS website at http://edis.ifas.ufl.edu.

2. Frederick M. Fishel, professor, Agronomy Department, and director, Pesticide Information Office; Florida Cooperative Extension Service, Institute of Food and Agricultural Sciences, University of Florida, Gainesville, FL 32611. 
50\%. Informed decision-making using the IPM approach ultimately influences a profitable agricultural production system and benefits the consumer by providing foods with minimal or no detectable pesticide residue.

\section{Protecting the Public}

As part of its program to regulate pesticide use, the EPA is responsible for ensuring that the public is protected from unreasonable health risks posed by eating foods that have been treated with pesticides. An important component of that effort involves setting "tolerances," which are the maximum amount of pesticides that may legally remain in or on food and animal feed.

When setting tolerances, the EPA must determine the maximum levels of pesticides likely to be found in food. The EPA accomplishes this by requiring pesticide manufacturers to submit data that answer basic questions about what residues are present in food and in what quantities. Examples of this field trial data include studies of residues found on crops grown in the field when pesticides are applied using the highest rate allowed by the pesticide product label. Manufacturers must also provide information on residues found in many processed foods, such as apple juice or tomato paste. Data on residues in animal products, such as milk or meat, are also required if livestock are exposed to pesticides directly or through residues in their feed.

In reevaluating the safety of existing pesticides, the EPA also uses monitoring data that show the levels of pesticide residues actually occurring in foods as they are harvested, processed, marketed, and prepared to be served (Figure 2). The EPA sometimes requires pesticide manufacturers to perform monitoring studies. Monitoring data often are also available from the FDA, USDA, and state agencies.

The EPA also requires a battery of toxicity tests in laboratory animals to determine a pesticide's potential for causing adverse health effects, such as cancer, birth defects, and effects on the nervous system or other organs. Tests are conducted for both short-term (acute) and long-term (chronic) toxicity. For cancer risks, the EPA evaluates multi-year tests of laboratory animals to estimate levels unlikely to pose more than a negligible risk. Tolerances are only approved if the expected exposure is below these health concern levels.

To evaluate chronic effects other than cancer, laboratory animals are exposed to different doses of a pesticide to determine the level at which no adverse effects occur. The highest pesticide dose that does not cause observable harm

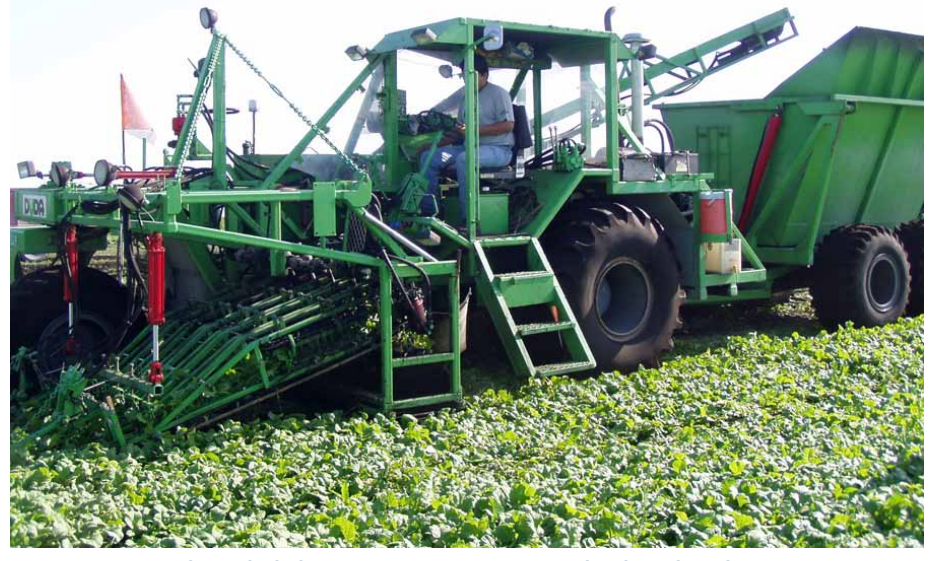

Figure 2. Fresh radish harvest occurs in South Florida. The EPA uses monitoring data that show levels of pesticide residues occurring in foods as they are harvested.

Credits: UF/IFAS Pesticide Information Office

or side effects in experimental animals is referred to as the No-Observable Adverse Effect Level (NOAEL). This level is divided by an uncertainty or "safety" factor (usually 100) to account for the uncertainty of extrapolating from laboratory animals to humans and for individual human differences in sensitivity. The resulting figure, termed the Reference Dose (RFD), is the level of exposure that the EPA judges an individual could be exposed to on a daily basis for a lifetime of 70 years with minimal probability of experiencing any adverse effects. The RFD generally is expressed in terms of milligrams of a pesticide consumed per kilogram of body weight $(\mathrm{mg} / \mathrm{kg})$ per day.

Next, EPA scientists determine how much of a particular pesticide residue the average consumer might ingest over a life expectancy of 70 years. One measure used to calculate lifetime exposures is the Theoretical Maximum Residue Contribution (TMRC). The TMRC assumes that the foods consumed will contain maximum amounts of pesticide residues. These calculations assume that the maximum allowable amount of a pesticide will be applied to $100 \%$ of the labeled crops, that the number of pesticide applications will be in accordance with the maximum allowed by the product label, and that the food commodities will be consumed daily for a lifetime. The TMRC is calculated by multiplying the tolerance on each crop by the average daily consumption of that crop. The individual TMRCs are then added to derive a single Theoretical Maximum Residue Contribution that serves as one of the indicators for theoretical exposure.

When comparing the TMRC and the RFD, the pesticide is believed harmless to public health when the TMRC value is below the RFD safety value. If the TMRC is above the RFD, 
the EPA reviews actual residue data or requires the development of such data to ascertain more realistic exposure estimates. This second exposure estimate incorporates "real world" residues into the calculations and is termed the Anticipated Residue Contribution (ARC). The ARC allows for a realistic refinement of the TMRC. Actual pesticide use, anticipated residues as determined in controlled field studies, the effects of processing, peeling, washing, and cooking on residues, and regulatory monitoring data represent the kinds of information used to evaluate the ARC alongside the RFD.

When the EPA considers a manufacturer's new request for the use of a pesticide on a food crop, the ARC and RFD are examined. The residue contribution from the requested use is added to the TMRC or ARC, and as long as it is below the RFD, a tolerance will be assigned for that use on that specific crop. Tolerances generally will not be approved when the ARC is above the health-based RFD criteria. Some pesticides are exempt from tolerance when they cause no adverse effects in any of the tests.

\section{Infants, Children, and Others}

The EPA recognizes that the diets of infants and children may differ substantially from those of adults and that infants and children consume more food for their size. As a result, they may be exposed to proportionately more pesticide residues. The EPA addresses these differences by combining survey information on food consumption by nursing infants, nonnursing infants, and children with data on pesticide residues to estimate their dietary exposure. The EPA also uses this process to estimate exposure for other age groups, as well as several different ethnic groups and regional populations. Information about pesticide exposure to infants, children, and other subgroups is then combined with toxicity information to determine the potential risks posed by pesticide residues. If risks are unacceptable, the EPA will not approve the tolerances.

The EPA uses several types of studies designed specifically to assess risks to infants and children. These include developmental toxicity studies, which examine risks to developing fetuses that result from the mother's exposure to pesticides during pregnancy; developmental neurotoxicity studies, which specifically examine the risks to the developing nervous system; and two-generation reproduction studies, which provide information about the possible effects on the health of both the individual and its offspring resulting from pesticide exposure.

\section{Annual Assessment of the U.S. Food Supply}

The USDA's Pesticide Data Program (PDP) annually tests a wide range of commodities in the U.S. food supply (Figure 3). The PDP tests fresh and processed fruit and vegetables, grains and grain products, nuts and nut products, milk and dairy products, beef, pork, poultry, catfish, corn syrup products, honey, pear juice concentrate, barley, oats, rice, bottled water, groundwater, and treated and untreated drinking water for pesticide residues. These data are important to ensure that the 1996 Food Quality Protection Act (FQPA) is implemented and followed. The FQPA requirements include stricter safety standards, especially for infants and children, and a complete reassessment of all existing pesticide tolerances. Thirteen states participated in 2010, including Florida. Sound conclusions about the U.S. food supply can be drawn from the PDP results because these states represent all regions of the United States and more than half the population.

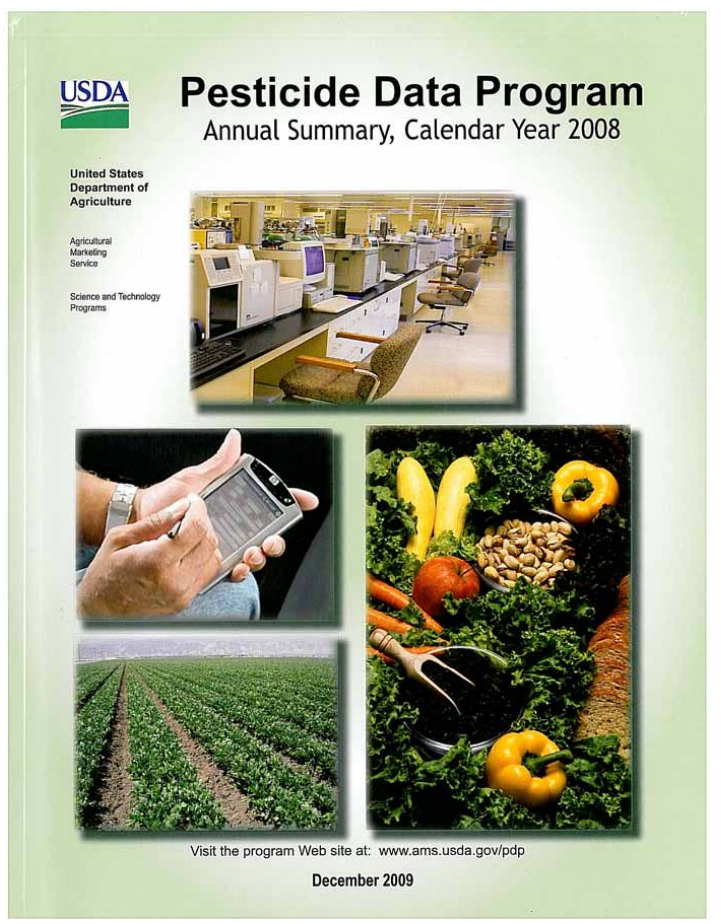

Figure 3. The USDA provides annual data summaries of pesticide residues tested on commodities.

Credits: UF/IFAS Pesticide Information Office

During 2010, the PDP tested 12,845 samples for various insecticides, herbicides, fungicides, and growth regulators. Of the 12,845 total samples collected and analyzed, 10,974 were fresh and processed fruit and vegetables. The remaining samples consisted of almonds, honey, catfish, corn grain, rice, groundwater, and treated and untreated drinking water. For fresh and processed fruit and vegetables, 
almonds, honey, catfish, and rice, approximately $73.8 \%$ of all samples tested were from U.S. sources, $23.8 \%$ were imports, $1.4 \%$ were of mixed national origin, and $1.0 \%$ were of unknown origin.

In 2010, excluding water and catfish, residues exceeding the established tolerance were detected in $0.25 \%$ of the 11,644 samples tested, and residues with no established tolerance were found in $4.3 \%$ of the samples. Catfish and water are not included in these calculations because residue levels, if found, are mainly the result of environmental contamination or transfer, rather than from registered agricultural uses on the commodity.

PDP laboratory operations are designed to detect the smallest possible levels of pesticide residues, even when those levels are well below the EPA's established safety margins. It is important to note that the mere presence of a pesticide on food does not indicate the food is unsafe. For samples containing residues, the vast majority of the detections were well below established tolerances and/or action levels. The reporting of residues present at levels below the established tolerance serves to ensure and verify the safety of the U.S. food supply. Of all samples collected and analyzed, 85.4\% were fresh fruits and vegetables, many of which are often eaten in a fresh, raw state. Health experts and the U.S. Food and Drug Administration agree washing fresh fruit and vegetables before eating is a healthful habit. Consumers can reduce pesticide residues if they are present by washing fruit and vegetables with cool or lukewarm tap water.

\section{Conclusion}

The EPA's tolerance process is protective of human health because it is based on extensive testing and a combination of conservative assumptions and risk assessment practices developed using current scientific knowledge. The USDA PDP verifies the tolerance process is effective through its testing protocol and through the results of its findings reported on an annual basis. At the same time, the EPA is working to make federal standards more protective of infants and children and to better understand the potential risks of pesticides.

\section{Additional Information}

Fishel, F. M. 2010. The EPA Conventional Reduced Risk Pesticide Program. PI224. Gainesville: University of Florida Institute of Food and Agricultural Sciences. http://edis.ifas. ufl.edu/pi224.
Fishel, F. M. 2005. Pesticide Residues. PI69. Gainesville: University of Florida Institute of Food and Agricultural Sciences. http://edis.ifas.ufl.edu/pi106.

Mossler, M. A. 2005. Reduced Use of Restricted and Danger-Labeled Pesticides in Florida Bell Pepper Production (1992-2004). PI86. Gainesville: University of Florida Institute of Food and Agricultural Sciences. http://edis.ifas. ufl.edu/pi123.

Mossler, M. A. 2005. Reduced Use of Restricted and DangerLabeled Pesticides in Florida Fresh Market Tomato Production (1992-2004). PI87. Gainesville: University of Florida Institute of Food and Agricultural Sciences. http://edis.ifas. ufl.edu/pi124.

Mossler, M. A. and F. M. Fishel. 2006. Pesticide Tolerances and Exemptions. PI118. Gainesville: University of Florida Institute of Food and Agricultural Sciences. http://edis.ifas. ufl.edu/pi155.

Olexa, M. T., and Z. Broome. 2011. Handbook of Florida Water Regulation: Food Quality Protection Act. FE589. Gainesville: University of Florida Institute of Food and Agricultural Sciences. http://edis.ifas.ufl.edu/fe589.

USDA Pesticide Data Program. 2010. Annual Summary, Calendar Year 2010. Accessed January 2013. http://www. ams.usda.gov/pdp. 